\title{
HOMENAGEM
}

\section{Maria Angélica Rebello. 28 Anos de Revista.}

\section{A Redação}

\begin{abstract}
Maria Angélica Rebello é uma das pessoas que temos em especial na vida. Quando a ela nos referimos, de imediato, duas virtudes vêm à mente: persisténcia e perfeccionismo.

Nas Arcadas houve tempos de trabalhos, juntos, em 1976, na Revista da Faculdade. framos colegas e companheiros, outrossim, na Faculdade de Comunicação Social «Cásper Líbero». Outras épocas, outros comportamentos sociais - que relembram vidas acadêmicas dedicadas e repletas de animosidade. E ânimo nunca faltou à Maria Angélica, enibora com passagens nem um pouco agradáveis, nos seus 28 anos de Revista. o atropelamento que sofrera é extmplo da força de vontade que sempre tivera em atividades particular e profissional.
\end{abstract}

Lembro-me da Seção instalada no $3 \circ$ andar e da janela a via chegar ao estacionamento da Faculdade, na Rua Riachuelo. Pequenina, nervosa no andar, sempre aflita para ver o próximo fascículo completado lá estava ela em minutos para o reinício dos trabalhos.

Apesar de o nervosismo imperar no modo de ser, Maria Angélica nunca desprezou a gentileza. Mulher polida, tanto no tratamento quanto na expressão da palavra.

Foram tantos anos de dedicação e colaboração à Faculdade de Direito - somente a Permuta nacional e internacional fez que nossa Facuidade fosse apreciada e agraciada por todos os institutos juridicos do mundo - que preferimos contar com a própria jornalista e advogada na narração de sua vida.

Aceitou, gentilmente, intitulando-a Minha Vida, Meu Trabalho, cuja exposição está a seguir:

\section{Minha Vida, Meu Trabalho}

Eis-me dando a público, por gentileza e mera condescendência da Douta Congregação desta Faculdade e da DD. Comissão da Revista da Faculdade de Direito, a história de minha vida e trabalho, meu "diário de bordo". Explico. "Diário de Bordo" é título que, muito espirituosa, deu uma de minhas auxiliares aos currículos que os homenageados por esta Revista nos remetiam para a redação de notícias, posse de cátedra, jubileu etc., e que adotei prazeirosamente. 
$\mathrm{Na}$ verdade, a vida é uma viagem longa ou curta, acidentada ou calma, cujo relato cronológico assemelha-se a diário de bordo.

Os currículos que recebíamos eram todos mananciais de ricas informações sobre a vida profissional dos mestres, de fatos, atos e obras tão importantes que mereciam ser registrados "ad perpetuam rei memoriam". Melhor disse ainda Professor Dr. Geraldo de Camargo Vidigal ao remeter-me o seu: "aqui vai meu passaporte para a glória."

Glória, sem dúvida, que não mereço mas desvanece-me até o fundo da alma é o registro nestas páginas que completam seu nonagésimo aniversário, dos pequenos fatos de minha viagem pela vida; repletos, porém, de amor pelos que me cercaram desde a infância e de encantamento, alegria e entusiasmo por tudo que fiz, bem ou mal, vibrando em cada ato intensamente, seja talvez o único mérito.

\section{Dados Pessoais e Primeiros Estudos}

Consta de documentos oficiais que nasci em Itatiba, Estado de São Paulo.

Filha legitima de Pedro Cardoso Rebello e de D. Anna Kisth Rebello; foram meus avós o capitão Miguel Cardoso Rebello e D. Rita do Amaral Rebello; Victório Kisth e D. Maria Thereza Danielle Kisth.

Fiz os primeiros estudos com D. Rita do Amaral Rebello, tia do lado paterno, que além de alfabetizar-me antes dos 6 anos, ensinou-me música e piano naquela idade. Mais ou menos aos 7 anos apresentava-me em público, pela primeira vez, já em outra cidade, Bragança Paulista, no Colégio Sagrado Coração de Jesus, dirigido por freiras da ordem religiosa espanhola "Filhas de Jesus"

Desde essa idade, meus irmãos, D. Maria José Rebello Nahas e Dr. Geraldo Rebello, e eu recebíamos rigorosa formação moral, religiosa e cívica quase medieval, tanto por parte de nossos pais como das tias; as idéias absorvidas então de dignidade pessoal, de honra, de amor à verdade, à Pátria influenciaram-me pela vida afora, a despeito de temperamento obstinado, independente e indócil, ao mesmo tempo alegre, ardoroso, impetuoso.

Durante o ginásio que completei no mesmo Colégio Sagrado Coração de Jesus, estudava música e piano e lia muito, preferindo biografias de personalidades ilustres, estadistas, literatos nacionais e internacionais, a própria literatura clássica, poesias, história Pátria e Mundial, até a revolução bolchevista responsável pelo massacre da família imperial russa, que me impressionou muito na ocasião.

Não sei se a leitura constante ou influência de minha tia despertaram em mim amor tão grande ao Brasil que me prometia fazê-lo amar pelos futuros alunos; revoltava-me saber que o mundo quase o desconhecia. Nasciam então sonhos utópicos: fazer o Brasil conhecido 
no mundo inteiro! Como? Uma simples professorinha caipira?! Quero dizer, do interior. Mas sonhava! Sonhava arrebatadamente!!!

Como já disse, continuava o estudo de piano com minha tia, tendo recebido, também, aulas de interpretação com D. Maria da Fontoura Costa, ex-aluna de Chiafarelli, durante 6 meses ou um ano, não me lembro bem, e algumas com outra tia paterna que no século chamava-se Benedita do Amaral Cardoso Rebello, ex-aluna de Vitória Serva da Escola Chiafarelli e de Franceschini. Tornou-se religiosa Dominicana com o nome de Irmã Maria Gertrudes do Sagrado Coração e fundou o conservatório de Limeira, tendo recebido, recentemente, homenagem da cidade inteira.

Devia ter mais ou menos 12 ou 13 anos quando conheci no Hotel Carvalho de Bragança, apresentada por querida amiga Diná Maria Martins, filha dos proprietários, o sr. Rossini Camargo Guarnieri que lá se hospedava. Ouvindo-me executar uma peça de Grieg, entusiasmou-se e não se conformava com minha permanência no interior, achando que devia vir a São Paulo para aperfeiçoar-me. Meus pais não permitiriam por ser muito criança. Ofereceu-me então uma coleção de peças compostas por seu irmão Mozart Camargo Guarnieri, notável compositor contemporâneo, tendo sido estudadas e executadas quase todas, algumas de grande dificuldade técnica e interpretativa.

Por essa época, enquanto fazia o ginásio, apresentei-me inúmeras vezes em público, tanto em Bragança como em São Paulo, executando peças de Brahms, Liszt, Chopin, Beethoven, Mozart e outros, em salões particulares e no Liceu Coração de Jesus em São Paulo e em salões de Bragança Paulista. Concentro-me sempre em tudo que faço. $\mathrm{Na}$ primeira audição dada em São Paulo, em salão particular de alta classe, executava Carnaval de Grieg tão absorta na música e era tão grande o silêncio que ao estrugir de palmas assustei-me. De outras vezes, cheguei a chorar de emoção ao executar peças de Tschaikovsky, Barcarolle, op. 6 e Romance.

Mais tarde, já graduada professora normalista, passei a estudar com Maestro Demétrio Kipman (1), sob cuja regência executei, como solista, dois concertos com a Orquestra Amadores da Arte Musical de Bragança Paulista: O concerto em sol menor de Mendelssohn - Bartholdi e o Concerto $\mathrm{n}^{\circ} 1$ - op. 23 de Peter I Tschailkovsky, com 97 páginas.

Este último foi preparado em um ano e o mestre exigia, nos últimos meses, que estudasse nota por nota, acorde por acorde, levantando de cada vez dedos, pulsos ou braços, vagarosamente, para perfeição de "toucher", 6 a 8 vezes por dia; e uma ou duas vezes no

(1) Maestro Demétrio Kipman, de origem nobre da Rússia, naturalizado brasileiro, fundou em Bragança Paulista a Sociedade Amadores da Arte Musical " lecionou línguas e piano naquela cidade e em São Paulo. Tanto fez pela música e pela juventude que as cluas cidades o homenagearam dando seu nome a ruas. Atualmente há em Bragança Conservatório com seu nome. 
tempo certo. Jamais poupei-me esforços para realizar algo e pacientemente cumpria a recomendação. Massacre verdadeiro.

Quem conhece a dificuldade técnica desse concerto e das demais peças que citei, há de concordar que o estudo de piano como me exigiram os vários mestres, não perdoando qualquer deslize ou descaso de acidentes musicais, legatos, stacatos, ralentandos, fermatas, fraseados etc. foi de extraordinária valia para o trabalho que realizei mais tarde, no aprimoramento gráfico da Revista da Faculdade de Direito, uniformizando tipos de títulos, intertítulos, notas de rodapé, de bibliografias e outros, e na revisão de textos. A observação de acidentes musicais e a observação cuidadosa de acidentes topográficos são paralelas, embora a primeira, interpretativa de música, contenha emoção.

A memória auditiva e mental desenvolvida na decoração das peças, sobretudo dos dois últimos concertos, auxiliou-me no estudo universitário tanto do direito e cursos de extensão universitária, como no estudo de jornalismo. Trabalhando intensamente quase não sobrava tempo para o estudo; em grande parte devia contentar-me em ouvir as preleções e guardá-las na memória.

\section{Ensino}

Concluído o Curso Normal, apesar de ter sido aluna difícil quanto ao comportamento, mas com boas notas de Pedagogia, Psicologia, Sociologia e Didática, lecionei no mesmo colégio.

Naquele ano para minha alegria, mudou a Superiora. Apresentei-me e confessei: fui péssima aluna mas pretendo ser ótima professora. Qual não foi a surpresa ao contratar-me. Transformei-me; dediquei-me de corpo e alma às minhas alunas. Alfabetizei duas ou três turmas, cada uma em menos de dois meses. No fim do ano, as meninas liam corretamente, sem tropeços, como adultas, e escreviam corretamente suas pequenas orações. Tinham base firme de aritmética e conheciam rudimentos de História e Geografia.

Já no curso primário cumpri o plano de fazer meus alunos amar o Brasil. Foi com lições de História, nos finais de aula. Tão pequenas e tão sensiveis ao bem! Lia, para que conhecessem, vidas de brasileiros e fatos da História Pátria de livro que talvez não mais exista: Sombras que Vivem. Era escrito com tal vigor de idéias, descrevia com tal colorido fatos e homens a ponto de comover. Minhas pequeninas sequer piscavam para ouvir bem as histórias, e, confessaram-me algumas: até chorei! Assim começaram a amar os heróis brasileiros e a dar valor a terra em que nasceram.

Logo, porém, minha família veio para São Paulo e fui lecionar no Colégio Nossa Senhora de Sion de Higienópolis. Deram-me as alunas do quarto ano primário. 
Vejo-as ainda, encantadoras nos uniformes impecáveis; torsal verde pendente da cintura, indicando a classe, chapéu de aba larga em feltro azul marinho, mãos enluvadas. Finas, bem educadas, inteligentes, eram preparadas para a elite social. Mas, realmente, agruparam-se 40 ou mais meninas irriquietas, falantes, peraltas para me endoidecer. Algumas contavam 13 ou 14 anos, confundindo-se com a jovem mestra, que felizmente ficava em tablado alto de dois ou três degraus. Precisei usar de certa violência, uma só vez, para fazer-me respeitar e consegui.

A sala era grande e clara e dava para o parque com plantas e árvores que me encantavam. Bem perto da sala, junto à janela às costas da mestra, um viveiro onde morava uma arara. Colorida e barulhenta imitava as alunas gritando o tempo inteiro "Masel, Masel" ("Masel" é corruptela de Mademoiselle) "Masel, Masel"! Quando não eram as meninas a arara!

Um dia, logo no primeiro mês, perdi a paciência. Levava um pacote de provas, mais de quarenta, para correção e debate oral; delicadamente pedia silêncio, mas a conversa continuava animada; eu a esperar e pedir silêncio, até que na terceira ou quarta vez, num impulso indignado, com toda força, estourei sobre a mesa o pacote inteiro de provas que voaram até a última carteira. - Corrijam vocês mesmas, disse irritadíssima, e saí da sala para a Diretoria. Felizmente tive apoio da Superiora que me deu carta branca. A contar de então não houve mais problemas com disciplina.

Percebi que as novas alunas não estavam suficientemente preparadas e adotei método próprio; no primeiro semestre intensifiquei o estudo de português e aritmética, relegando para o $2^{\circ}$ semestre as demais matérias, excluindo História Pátria, que a título de lazer, contava nos fins das aulas, movimentando-a com desenhos rudimentares na pedra. Não precisavam estudar; aproveitava-me de novo da História para despertar nas alunas o amor à Pátria. Aproveitava-me de todas as circunstâncias para incutir-lhes amor à verdade, à liberdade consciente, à justiça, à lealdade.

O método deu esplêndido resultado, pois voltara ao princípio, aos rudimentos de Português e Aritmética para desenvolver o programa racionalmente, em alicerce firme, seguro. A maior parte das alunas passou para o ginásio sem curso preparatório e a assistente do curso primário, "soeur" Ana Eugênia, convidou-me a dar aulas de português e aritmética em todas as classes; seria sobrecarga perigosa e arriscada, não pude aceitar.

Com outras três turmas segui o mesmo método, com mesmo esplêndido resultado.

Mais tarde, já bacharel em Direito, tive mais uma experiência didática e pedagógica. 
Após testes especiais, fui convidada a lecionar Português no Curso Tales de Preparação para Oficiais da Aeronáutica. Não me lembro bem se era para Oficiais ou aspirantes a Oficiais. Lembro-me, no entanto, que um colega procurou dissuadir-me pois lecionara naquele curso e não suportara o peso. Eram os jovens, dizia ele, tão indisciplinados e mal criados que não se conseguia dar uma aula.

Fiz questão no início de relatar certos traços de minha personalidade e eventual leitor não duvidará que enfrentei a "turba", como dizia o colega.

Usando saltos de $10 \mathrm{cms}$., levantava o cabelo prendendo-o à nuca, para dar-me aspecto mais grave. Tenho gênio e fisionomia alegres o que engana, involuntariamente, a quem não me conhece.

No princípio, intimamente apavorada, assestei carranca.

O primeiro e único a brincar foi um japonezinho. Convidei-o a retirar-se da sala insistindo para que não voltasse. Não saíu. Desculpou-se. Perdoei.

Tive então, a contar desse dia, a experiência mais cara, a lembrança mais querida como professora. Tornei-me amiga dos alunos. Reunía-mo-nos antes da aula para conversar; aprendi propositadamente marcas de carro, acompanhei a política, e já conhecia um pouco a respeito de aviões e naves espaciais e "foot-ball", assuntos prediletos dos jovens. Nessa conversa diária conquistei-lhes a confiança, a amizade e nas aulas o respeito.

Encontrei-os, jovens que já haviam concluído o científico e clássico daquele tempo, sem preparo algum em Português; excluindo dois ou três, os demais precisariam voltar ao princípio. Foi o que fiz. Preparava diariamente as aulas sintetizando em quadros sinóticos a matéria a ser dada, desde a fonética. Depois redação de pequenas orações, de curtos períodos para finalmente chegar a composições. Dava, também, aulas práticas e orais de emprego correto de verbos, pronomes e concordância. Resultados bons gradativamente e finalmente muitos foram aprovados.

Entra em vigor pela $8^{a}$ vez o plano da primeira juventude: fazer dos alunos pessoas leais, dignas, honestas que amassem estremecidamente a Pátria.

Que almas tão lindas e puras as dos jovens, que massa tão fácil de moldar, que potencialidade vigorosa de entusiasmo, de ação, inteligência, de sensibilidade, de amor!

Das lembranças que me ficaram, relato duas apenas para ilustrar o que afirmo. 


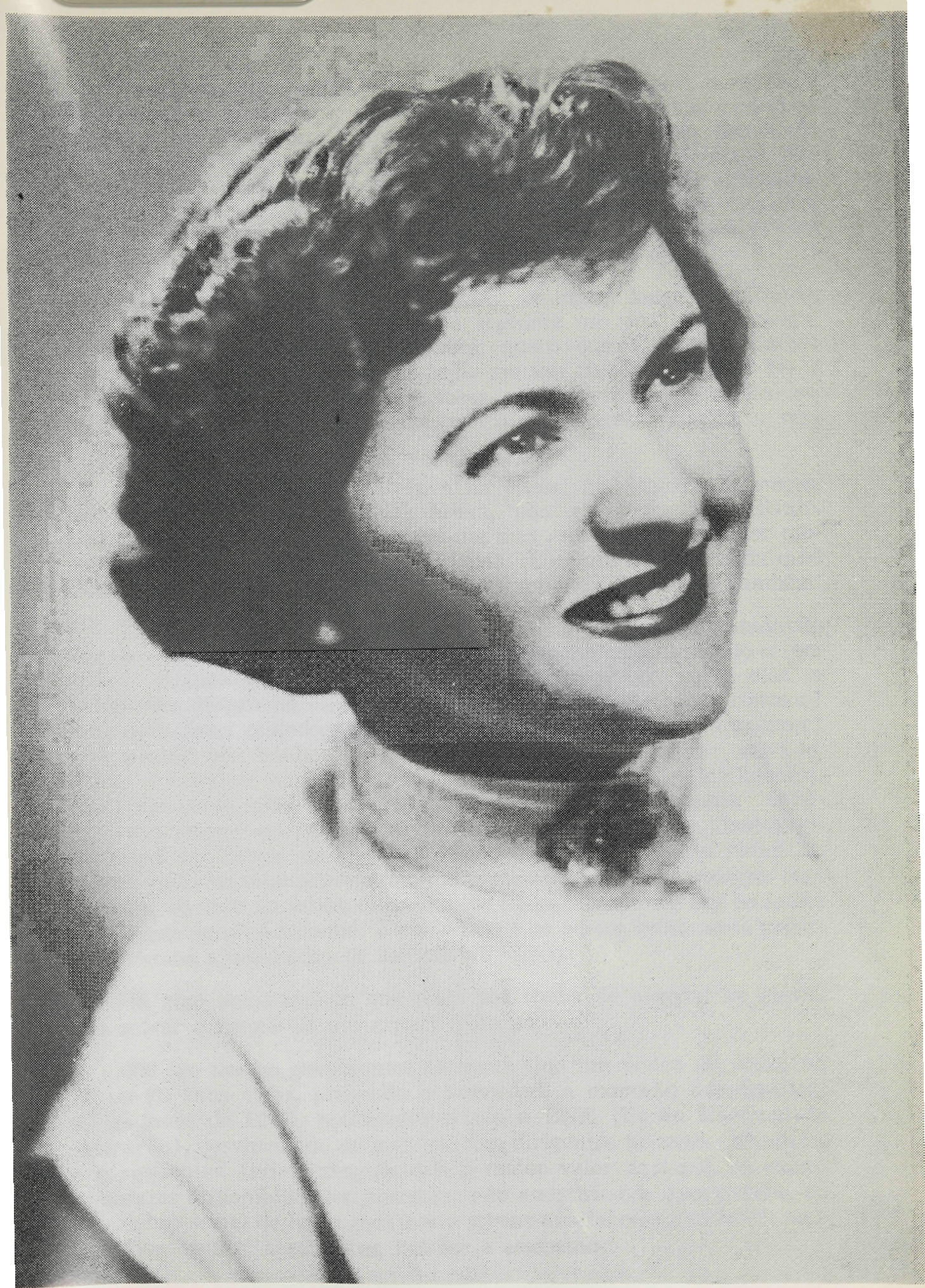

Maria Angélica Rebello, em 1954, ao iniciar os serviços da Revista. 
Fiz várias explanações sobre a necessidade de serem honestos e respeitarem a si mesmos, sobretudo futuros aviadores que poderiam chegar a ser Presidente, como Castello Branco na época; nomeando as riquezas do Brasil que para ser uma das maiores, ou a maior $\mathrm{Na}$ ção do mundo, somente necessitasse de homens honestos e competentes, estabelecemos um acordo, democraticamente: ninguém mentiria, em classe ou fora dela, e para exercitar quando fizéssemos provas ninguém usaria cola, que na verdade é usurpar nota de outro.

Aconteceu que foram fazer prova simulada longe da Escola, sem a presença da mestra. No dia seguinte um dos alunos chega-se-lhe para dizer: escute, professora, quero que a senhora saiba: "ontem, no simulado, um colega pediu-me um cigarro. Ofereci-lhe o maço mas o Diretor pensou que fosse cola e retirou-nos as provas. Não faz mal que ele pense assim, quero que a senhora saiba a verdade; eu não estava colando".

Outras vezes, em dia de prova na classe, dizia-lhes: são moços, têm responsabilidade pelo que fazem, não precisam de vigilante. Lembrem-se do acordo. Ausentava-me mas retornava a qualquer momento sem ser pressentida. Que delícia! Absoluto silêncio, cada qual concentrado em sua prova. A nota era minha e a alegria também!

Havia entre os alunos um rapaz inteligente, mais adiantado do que os outros, que se desviara, por más companhias, afundando-se em vícios. Alguns dos alunos reclamavam sua presença entre eles, e indignados diziam-me - como permite a senhora esse rapaz conosco? Respondia-lhes: quando alguém está se afogando, ajudam a morrer? não saberá que conheço seus problemas, vamos procurar salvá-lo. Passei a exaltá-lo em classe, sua redação, os desenhos, a inteligência, encarregando-o, inclusive, de redigir lições e dá-las aos colegas. O rapaz entusiasmou-se, pasou a freqüentar mais as aulas e finalmente ingressou na Escola de Cadetes. Recebi, então, o prêmio maior de minha vida: os alunos preparam-me carinhosamente um caderno com recortes, os mais variados, de aviões, de naves espaciais e até de Laika e disseram agradecendo-me: o nome dele e os nossos estão neste caderno. Vamos ajudá-lo, há de ser oficial!

Há algo neste mundo que mais nos encha de alegria, de glória, que salvar o futuro de um rapaz? Não há.

Oh! Se nossos governantes tivessem tido um pouco de visão, há 30 ou 20 anos atrás, prevendo o previsível, a explosão demográfica; se ao invés de BNH, houvessem criado o BNE (Banco Nacional da Educação), desvinculado de política, com dirigentes honestos, altruístas e competentes, teriam resguardado o maior valor nacional, as extraordinárias disponibilidades juvenis, e não assistiríamos estarrecidos, ao descalabro social de hoje: meninos e jovens analfabetos, famintos, maltrapilhos, vadios, assaltantes, ladrões e assassinos! 


\section{Vida Universitária}

\section{Curso de Ciências Jurídicas e Sociais - USP}

Para melhor desempenhar as atribuições que me eram afetas, na Redação e Permuta Internacional da Revista da Faculdade de Direito, resolvi estudar Direito.

Fiz antes o curso preparatório com professor Castelões, estudando Português e Latim e um pouco de Francês com professor Tolosa no mesmo curso.

Ingressando no Curso Jurídico em 1957 o concluí em 1961 e colei grau em 1962.

Além do currículo normal do curso de Direito que, infelizmente, não pude desenvolver como era meu desejo, pelo trabalho intenso da Revista, mas tendo boa memória auditiva em virtude do estudo da música já referido, fiz vários cursos de extensão universitária e o antigo Curso de Especialização nas cadeiras de Filosofia do Direito, Processo Civil e Direito Penal.

Sem dúvida esse preparo ajudou-me a levar a termo a redação que me cabia, na Revista, tanto na seção de Crônica ao biografar professores homenageados, ao comentar suas atividades jurídicas, ao condensar discursos eminentemente jurídicos para "leads", ou notícias culturais, como ao redigir comentários, notas, até para a revisão e Editorial; muitas vezes tive que pesquisar e reestudar certas matérias, caso, por exemplo, da "lead" para a Carta aos Brasileiros.

Examinava, também, colaborações que não eram somente de nossos professores, mas de fora. Se apresentassem má redação ou comprometessem de qualquer forma a Faculdade ou a Revista, apresentava-as à Comissão de Redação que em geral concordava com a suspensão do trabalho. Isto aconteceu várias vezes.

Ajudou-me, inclusive, no critério para escolha de Revistas de Direito Internacionais para permuta, que a contar de certa época precisaram ser muito selecionadas em virtude de falta de espaço na Biblioteca e limite de tiragem da nossa.

As lições preciosas que recebi nesta casa auxiliaram-me, também, na vida particular, ao administrar condomínios, resolver problemas familiares ou de amigos e os meus, no âmbito administrativo e imobiliário.

Vivi intensamente o período acadêmico tendo sido um dos elementos fundadores do Coral Acadêmico, isto é, pertenci à primeira turma de coralistas, participando de muitas audições, inclusive em outros Estados e em Brasília quando era presidente o Senhor Janio Quadros e ministro da Educação, parece-me, nosso Professor Canuto Mendes de Almeida. Participei de muitos movimentos estudantis e até das "pinduras". 
Pertenci à Diretoria do Departamento Feminino do Centro Acadêmico XI de Agosto, primeiro como Tesoureira, a seguir como Secretária e finalmente como Diretora, cargo que apenas assumi renunciei, por razões políticas.

Ainda como estudante de Direito, dei duas entrevistas sobre a Revista da Faculdade de Direito, uma para um dos jornais acadêmicos da época, o Libertador, de 15-10-1957 com o título Mensagem de Cultura Jurídica, em que o repórter se refere à redatora assim: "com um entusiasmo desmedido mostrou-nos a secretária de redação os arquivos, a correspondência. ".

Outra foi de página inteira à Folha da Manhã, verdadeiro relatório sobre o movimento da Secretaria da Revista. Essa página foi conservada até há pouco mas perdeu-se em mudanças, por isso não me recordo perfeitamente se foi à Folha ou à Gazeta, mas entre 1957 e 1959.

Dei também, como bacharelanda, entrevista sobre o Parlamentarismo que se projetava para o Brasil em 1961, para a Gazeta ou Folha, também não me lembro, perdeu-se o recorte.

Mais tarde, no ano do Sesquicentenário de fundação dos Cursos Jurídicos no Brasil, dei nova entrevista para a Informações da Universidade de São Paulo, $\mathrm{n}^{\circ}$ 21, de maio de 1977, com a seguinte chamada "A Revista da Faculdade de Direito Mostra um Século de História Jurídica do País" e fez-se um resumo da história à p. 3, com o seguinte título: Desde 1893 Revista Representa Direito.

Quando estudante da Faculdade de Comunicações Sociais Cásper Líbero participei de um júri simulado pela TV Gazeta sobre aborto.

\section{Cursos de Extensão Universitária}

Como estudante de Direito, freqüentei vários cursos de extensão universitária, entre os quais: RUSP.

Curso sobre Problemas Fundamentais do Brasil patrocinado pela

Curso de férias do Centro Acadêmico XI de Agosto. Diploma de Aproveitamento por ter freqüentado assiduamente o curso sobre "Classificação das Ações e das Sentenças", ministrado na Faculdade de Direito da USP pelo jurista Professor Pontes de Miranda em 1959.

Certificado de conclusão do Curso de Extensão Universitária da RUSP sobre Potencial e Poder Nacional, patrocinado pela RUSP com a cooperação da Escola Superior de Guerra de 04-9-55 a 06-11-59 na Faculdade de Direito da Universidade de São Paulo.

Certificado de freqüência às aulas conferido pelo Centro Acadêmico XI de Agosto do Curso de Direito Tributário na Faculdade de Direito da Universidade de São Paulo, patrocinado pelo Departamento Cultural em 1957. 
Certificado de conclusão do curso de Literatura Contemporânea, realizado nos meses de agosto-setembro de 1960.

Diploma de aproveitamento referente ao curso sobre Aspectos da Parte Especial do Código Penal proferido no $2^{\circ}$ semestre de 1959 na Faculdade de Direito da Universidade de São Paulo em 1959.

Da mesma Sociedade Brasileira de Criminologia e Ciência Penitenciária, diploma por conclusão do curso sobre Crimes Contra os Costumes, proferido na Faculdade de Direito da Universidade de São Paulo no $1^{\circ}$ semestre de 1958.

Certificado de frequiência ao curso de Direito Tributário patrocinado pelo Centro Acadêmico XI de Agosto e ministrado por uma plêiade de nomes ilustres entre os quais Aliomar Baleeiros, Alcides Jorge Costa, Theotônio Monteiro de Barros Filho e Ruy Barbosa Nogueira em 1958.

\section{Curso de Comunicação Social na Fundação Cásper Líbero}

De 1974 a 1976 fiz o Curso de Comunicação Social - Jornalismo, na Fundação Cásper Líbero.

Mal iniciara o curso, sofri acidente muito grave que me causou leve trauma craneano afetando-me o sistema nervoso. Licenciei-me então da Faculdade de Direito para tratamento, por longo tempo; mas continuei meu trabalho apesar da licença, para concluir o volume de 1973 da Revista, comemorativo de seu octogésimo aniversário de fundação, durante seguramente seis meses, deixando apenas a segunda revisão para a substituta, Bibliotecária, D. Maria Tereza Fusco, que aliás encerregou-se do volume de 1974. ${ }^{(*)}$

Continuei os estudos de Jornalismo com certa dificuldade nos exames: entrava em pane mental e esperava acalmar-me para coordenar idéias.

Os trabalhos feitos fora de exames, com calma, receberam notas altas. Colei grau em 1977, então já em exercício na Faculdade de Direito.

Durante esse curso participei da $7^{\text {a }}$ semana de Estudos de Jornalismo - Especialização no Jornalismo - Situação Atual e Tendências, realizada na Escola de Comunicações e Artes - Departamento de Jornalismo e Editoração - da Universidade de São Paulo, em junho de 1976, portanto no último ano.

Este curso foi feito por imposição da RUSP para reestruturação de cargo; no entanto me coaduno ao jornalismo pela dinâmica, vibração, perquirição e comunicabilidade. Embora tivesse suficiente prática, 20 anos, e houvesse auferido lições freqüentes de jornalismo

(*) Entre 1979 e 1981, licenciei-me novamente para tratamento de saúde mas continuei os trabalhos da Revista em horários convenientes e em minha residência. Fui substituída, de fato, pela Bacharel Sônia Regina Ramos de Oliveira. 
com os diretores da Revista, Professor Miguel Reale e Ataliba Nogueira, o aprendizado foi bom para jornalismo popular, certa técnica de redação, titulação etc.

\section{Na Redação da Revista da Faculdade de Direito}

A vida dá muitas voltas. Deixara Sion e trocara o piano pelo amor. Em 1954 via-me trabalhando como funcionária pública na Biblioteca desta Faculdade e auxiliava a bibliotecária chefe D. Celina Cristiano de Souza na redação da Revista, por pouco tempo, pois D. Celina mudou-se para os Estados Unidos.

Era na época membro da Comissão de Redação e diretor responsável, Professor Dr. Miguel Reale, cuja experiência jornalística vinha-lhe dos bancos acadêmicos. Dinâmico, atuante, inteligência fluindo espontânea como água de fonte e bondade também (fui testemunha disto por 25 anos) ; era respeitado e acatadas suas opiniões por toda a Congregação e Diretoria. Pelo menos quanto à Revista garanto: não houve iniciativa sua que não se concretizasse até determinada época.

Resolveu então separar a Revista da Biblioteca e instalar a Redação em sala própria, concentrando todas as atividades afetas, redação, controle de acervo, distribuição, difusão, permuta internacional, etc., etc., etc.

Corno estava comigo a matéria em preparo deixada pela Bibliotecária fui a encarregada de reorganizar todos os serviços, inclusive a permuta internacional.

Estava ali a oportunidade de concretizar o sonho da primeira mocidade, fazer o Brasil conhecido no mundo, e como! Difundindo a cultura jurídica das Arcadas, as quais já amava e admirava em 1954, pelo mundo inteiro. Exultei!

Sem "dó nem piedade" de mim mesma, não considerava ou limitava horários trabalhando na Faculdade até altas horas ou em casa até de madrugada; não considerava salário que até 1975 era ínfimo; nem tarefas fazendo de tudo: era servente, faxineira (varri sala e tirei pó) contínuo, datilógrafo, correspondente, coordenador de matéria, revisor e redator, entendia-me com os colaboradores e imprensa. Era um Deus nos acuda!

Mas tinha objetivo que não era material, era muito, muito maior. Era realizar um sonho de amor a minha terra estremecida, era fazê-la respeitada pelo mundo do Direito, em todas as partes do globo.

Por isso trabalhei com paixão, obstinação, sem esmorecer durante 28 anos a despeito dos mil percalços superados com sacrifícios inimagináveis, incríveis, decorrentes de falta de verbas, de auxiliares, de material, e muitos outros; em várias mudanças de diretoria, mudanças e mudanças da seção da Revista que desorganizavam o que se preparava 
com tanto cuidado, arquivos, fichários, acervo, obrigando-nos a recomeçar o que já estava pronto.

Para iniciar comuniquei-me com os consulados que me forneceram relações das Faculdades mais importantes de seus países e publicações; consultei a seguir a "Source de Documentation Juridique" que me foi dada por empréstimo pelo Professor Dr. Vicente Marotta Rangel, hoje digno diretor desta casa, então Livre Docente de Direito Internacional.

De posse dos dados, distribui circulares em português acompanhadas de versão em francês ou inglês conforme a língua do país, remetendo a Revista e propondo acordo de permuta aos centros jurídicos e revistas mais importantes, cuidadosamente selecionados.

A primeira parte do plano estava lançada. Quase todas as entidades aceitaram a proposta estabelecendo o acordo. Era necessário sistematizar o trabalho, aprimorar a parte gráfica da Revista cuidar da qualidade científica dos trabalhos. Felizmente a Comissão de Redação, na época, cuidava da colaboração. Em geral ratificava decissões do Diretor responsável, Professor Dr. Miguel Reale, que de sua parte dava à Secretária de Redação todo apoio necessário para o desenvolvimento dos trabalhos. Impressionava-me, então, a extraordinária acuidade mental de meu diretor. Nada lhe escapava: Professor Reale via e observava tudo de tudo. Que eu não tergiversasse!

No contato cada vez maior com entidades nacionais e estrangeiras, recebendo publicações jurídicas ou de Direito do mundo inteiro, do contato com Diretores e Imprensa elaborou-se então um plano de trabalhos que abrangia atividades de redação, de intercâmbio, de serviços afins e de serviço bibliográfico.

Esse plano era minucioso em todas as suas partes, especificando as atividades de cada setor e foi desenvolvido inteiramente até 1969, quando se elaborou o $1^{\text {\% }}$ Boletim Bibliográfico, última parte do plano.

Trabalho de fôlego que somente foi possível porque a Secretaria da Revista contava no período de 1968-1969-1970 com dois funcionários habilitados para as tarefas além da encarregada: Advogado Alfredo Barone que auxiliava na classificação dos artigos de especificadas matérias e línguas, elaborando fichas correspondentes e D. Alcina Ferreira Jorge, exímia datilógrafa. Além de seu próprio trabalho de classificação de certas matérias e línguas, a Secretária supervisava e conferia os serviços dos auxiliares.

Esse primeiro Boletim Bibliográfico de Publicações Recebidas em Permuta registrou aproximadamente 5.500 artigos de revistas, as mais importantes, recebidas apenas naquele trimestre, porque o Boletim deveria ser trimestral. Os artigos eram classificados por assunto, com indicação da Revista em que era publicado, ano, número de volume, fascículo e página.

Compiladas as fichas de cada assunto eram datilografadas em estêncil para mimeografagem, agrupadas as folhas e distribuídas aos 
diversos Departamentos conforme a especialidade. O Departamento de Direito Civil (professores) recebia a parte do Direito Civil, com a relação de todos os artigos publicados internacionalmente naquele periodo. Os professores de Direito Penal recebiam a parte de Direito Penal, assim por diante, e ficavam a par das últimas novidades na sua especialidade, vindas de todas as partes do mundo.

Foram elaboradas as fichas para o segundo Boletim com milhares de outros artigos que infelizmente ficaram arquivadas e perdidas, por falta dos auxiliares que logo a seguir foram enviados para outras Seções sem ser substituídos. Ficou a Secretária de Redação praticamente sozinha e não pode dar o mesmo rítmo aos trabalhos, cuja massa era tão grande que a afligia. Fazia então o essencial relegando os demais. Mas o objetivo principal tinha alcançado: difundir o Direito das Arcadas, quero dizer, do Brasil, pelo mundo afora pois até a Rússia solicitou a Revista que fez questão de mandar.

Foi lamentável. O Boletim era de grande interesse para a pesquisa e estudo nos diversos departamentos, tanto assim que recebemos várias cartas elogiosas e de incentivo, inclusive registro em Ata de sessão da Congregação, proposta pelo Professor Dr. Vicente Marotta Rangel, então catedrático de Direito Internacional.

Uma das cartas, a do Professor Antônio Chaves, catedrático de Direito Civil, que ainda não era elemento da Comissão de Redação, publica-se a seguir pois ilustra claramente o que se expōe.

São Paulo, 3 de julho de 1969

Senhor Diretor:

Desejo externar a Vossa Excelência a minha satisfação por ter recebido a relação da parte relativa ao Direito Civil de alguns milhares de artigos publicados nas revistas estrangeiras com as quais a da nossa Faculdade mantêm o regime de intercâmbio.

No momento em que o comodismo parece dominar tantos, merece que se reconheça o valor daqueles que, como D. Maria Angélica Rebello, não titubeiam chamar a si uma empreitada que deve ter-lhe consumido dezenas de horas de trabalho e de paciência.

A nossa Biblioteca está de parabéns por tão útil iniciativa, que permitirá aos interessados, através da leitura de algumas páginas, inteirar-se a respeito do que de mais atualizado e importante vem sendo publicado em tão grande número de revistas.

Oxalá não esmoreça o entusiamo pela iniciativa, que considero das mais importantes, e que com o correr do tempo poderá mesmo encontrar novas formas de aperfeiçoamento.

Rogando transmita à DD. Secretária de Redação as expressões do meu agrado, subscrevo-me, mui cordialmente,

ANTOONIO CHAVES

Ao Excelentíssimo Senhor

Professor José Pinto Antunes

DD. Diretor da Faculdade de Direito da U.S.P.

E. $M$. 
Naquele tempo alcançáramos o apogeu dos trabalhos com resul. tado fabuloso, como o Boletim documentava em seus milhares de artigos sobre tdos os ramos do Direito, como, por exemplo, Direito Esportivo, Cinematográfico e de Radiotelevisão, Automobilístico, de Direito Sanitário, Direito Canônico, Direito Aeronáutico, Direito do Autor, Política Internacional, etc., etc., etc..

Era uma verdadeira fortuna o que recebiamos em Revistas estrangeiras, porque fora o valor subjetivo da matéria publicada, todas ou quase todas eram primorosas sob vários pontos de vista, tanto técnicoeditorial, como na qualidade de papel, capas, etc., e conforme o país alto valor em dólares.

Como eram registradas no livro de tombo, em certa ocasião anotei o preço de cada uma em dólares, francos franceses, francos suíços, marcos, liras e demais moedas e fiquei abismada. Infelizmente não pude somar, não houve tempo.

Mas além de recebermos essa carga imensurável de publicações riquíssimas, recebíamos também obras importantes para resenha. Acontecia, porém, que os professores levavam-nas para a resenha mas não tinham tempo para fazê-la. Resultado: não devolviam as obras esperando tempo e os autores esperavam a Revista que não a publicava. Era um caso sério!

Publicam-se a seguir excertos dos relatórios de 1972 e 1973 que de forma especial documentam as várias atividades desenvolvidas e resultados.

\section{Do Relatório de 1972}

Constatou-se neste ano, de forma significativa, a projeção e receptividade internacional da "Revista da Faculdade de Direito", pelas numerosas solicitações de permuta, doação ou compra, além de seu registro bibliográfico em importantes revistas internacionais, tais como:

"Index to Foreign Legal Periodicals" - (Institut of Advanced Studies, London England).

"Revista de Derecho Español y Americano" - (Instituto de Cultura Hispanica, Madrid - España).

$\mathrm{Na}$ "Buchbesprechungen" - da (Hamburg Geselfschaft fur Volkerrecht und Auswartige Politik) ab verlag und Recht in Obersee, (Hamburg - Germany), teve o seguinte registro:

"Em vista do mercado de revistas fortemente flutuante na América Latina, parece justificado aludir-se ao contínuo aparecimento de uma das poucas revistas jurídicas realmente tradicionais do sul continente americano, mesmo que a esfera de ação procurada por ela não se identifique com a do VRU" (Tradução de Pedro Potiguara de Araújo Leitão).

Foi solicitada, inclusive, pela International Books Representatives Co. Ltd., com sede em Bogotá (Colômbia), figurando em seus salões de exposição, para futura distribuição por venda, e forma de pagamento a ser estabelecida.

Por anterior acordo, foi remetida à Triade, (Asociación de Información Bibliografica) para divulgação televisionada, dentro de seu programa de divulgação cultural e futura vendagem. 
Honrosa foi também a solicitação da "United Nations" (New York) para a resenha dos trabalhos da Uncitral que nos serão enviados proximamente, e a publicação, na "Revista da Faculdade de Direito", da "Memoria del Secretario General sobre la Labor de la organización - Capitulo III - Comisión de las Naciones Unidas para el Derecho Mercantil Internacional", o que se fará na Secção de Notícias Culturais do próximo número a ser publicado.

Outras obras de grande valor foram-nos enviadas para resenha, reconhecendo-se, pois, a aceitação internacional da Revista. Entre elas:

"La Società con un solo socio" de Angelo Grisoli, publicado pela CEDAMPadova, Itália;

"The Stand-By Arrangements of the International Monetary Fund" por Joseph Gold, publicado pela "International Monetary Fund", Washington D.C.;

"La Causa y la Comprension en el Derecho" de Carlos Cossio, publicado pela Juarez Editor S.A., Buenos Aires;

"Degeneration of Trade Marks" por Lars Holmqvist publicado pela Jurist Ochsamhallsvetareforbundets Forlags A.B. - Malmo - Sweden;

"Derecho Internacional Privado" de José Yanguas Messia, Parte Geral, 3ą edicion, Reus, S.A. Madrid;

"Das Neus Politische Strafrecht der DDR", por Walter Rosenthal, Franckfurt am Main - Berlin, 1968;

"Judicial Review in Mexico, a Study of the Amparo Suit", por Richard D. Baker, publicado pelo "Institute of Latin American Studies - University of Texas Press", Austin and London;

"El Control Jurisdicional de la Constitucionalidade en Venezuela y Estados Unidos", por Humberto Y la Roche publicado pela Universidad de Zulia — Facultad de Derecho.

As resenhas dessas obras ficarão a cargo de especialistas, a serem designados pelos chefes dos departamentos, e serão publicadas no volume 68-1973.

\section{PERMUTA INTERNACIONAL}

Pelos anteriores acordos de permuta esta Secretaria recebeu, em 1972, 1.835 exemplares de revistas periódicas, de procedência internacional, portanto nas mais diversas línguas, versando matéria de Direito em geral e especializado, ou seja, direito do autor, aeronáutico, cinematográfico, automobilístico, sanitário, esportivo, etc.. Esse material constitui verdadeira fortuna em moedas estrangeiras, e invulgar riqueza bibliográfica, que remetida à Biblioteca geral constituiu os "Indices de Periódicos Correntes", em sua maior parte, publicado pelo centro de documentação desta Faculdade.

Todos os números de revistas recebidas foram registrados no livro de tombo e agradecidos, um a um, por meio de postais impressos em várias línguas.

Após criteriosá pesquisa bibliográfica feita em 1971 e neste ano, foram selecionados cento e cinco novos Institutos e Revistas internacionais aos quais se propuseram permuta de publicações, remetendo-se-lhes, em outubro p.p., os últimos números da "Revista da Faculdade de Direito". Já se receberam algumas respostas, inclusive da "National Lending Library for Science and Technology" - (Yorkshire-England), que nos enviará, em permuta, três valiosas revistas inglesas:

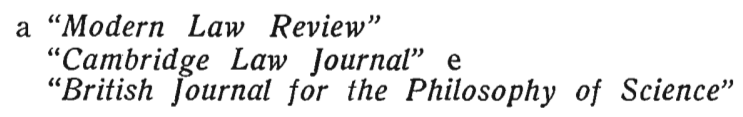

A "Organisation Mondiale de La Propriété Intellectuelle" (Genève-Suisse) já nos remeteu 
"Copyright", Monthly Review,

"Le Droit l’Auteur", Revue mensuelle, e nos remeterá, periodicamente,

"La Propriété Industrielle".

Também já aceitou nossa proposta a Biblioteca Universitária Alexandrina (Roma - Itália).

\section{CORRESPONDENCIA E EXPEDIÇÕES}

\section{Correspondência:}

a) Receberam-se 180 ofícios e cartas, em várias línguas, de procedência internacional, confirmando ou propondo-nos permuta ou solicitando números atrasados da "Revista da Faculdade de Direito"

b) Redigiram-se 265 ofícios e ofícios-circulares, em português, francês e inglês, para propostas de permutas, comunicações e esclarecimentos.

c) Receberam-se 893 postais de procedência internacional, agradecendo os volumes 66-1971 e outros especificados, remetidos em expedições gerais ou extraordinárias. Após a conferência de endereços e registro nas fichas de expedição, foram classificados por ordem numérica e geográfica e arquivados.

d) Foram sobrescritados e preenchidos, em várias línguas, 1.285 postais, agradecendo revistas recebidas ou solicitando números extraviados.

\section{Expedições:}

a) Expediram-se 1.220 exemplares do volume 66-1971, em doação e permuta, de acordo com o fichário de permuta, tendo sido feita a embalagem ordenada $e$ numerada de todos os exemplares, selagem, carimbagem e relações para o correio, após sobrescrição datilografada de todos os envelopes*.

b) Expediram-se, por solicitação de cartas, ou em proposta de permuta, 875 exemplares de números antigos e atuais, disponíveis. Todos os números expedidos foranı registrados em fichas de acervo e deduzidos do total. As embalagens, até três quilos, foram numeradas, carimbadas, seladas e relacionadas para o correio.

c) Foram expedidas 234 ofícios e ofícios-circulares, em português e eventualmente em francês e inglês, numerados, selados, carimbados e relacionados para o correio.

d) Expediram-se, por solicitação de professores, 135 exemplares de revistas disponiveis que foram deduzidos do acervo.

e) Expediram-se, por venda, 162 exemplares de números disponiveis, dentre os quais uma coleção completa, no total de $\mathrm{Cr} \$ 1.830,00$ (Um mil, oitocentos $\mathrm{e}$ trinta cruzeiros).

f) Foram expedidos 650 postais, numerados, carimbados, selados e relacionados para o correio.

\section{SERVIÇOS AFINS}

\section{Fichários:}

De Permuta - com 1.395 fichas, contendo: destinatário, em diversas línguas, registro numerado do material expedido, controle de recebimento, atualizado diariamente mediante conferência com o postal de recebimento. Foi integralmente refeito.

* Atualmente usam-se clichês para sobrescrição dos envelopes, isto desde 1979 ou 1980. 
De publicaf̧ão recebida - com 3.925 fichas, constando o título da publicação recebida, endereço, periodicidade; atualizado diariamente, a contar de agosto, mediante registro do número recebido e inserção de fichas de tíulos novos.

De entidades editoras (Série) - 1.360 fichas, constando nome e endereço da Instituição mantenedora da permuta ou doação; atualizado mediante registro de títulos novos de revistas recebidas ou de novas instituições. Não foi atualizado por falta de pessoal auxiliar.

De acervo - com 129 fichas, constando número de cada volume do acervo de cada edição. Atualizado mediante o registro do destinatário, número de expedição e dedução do total do acervo.

De clichês - com 560 fichas, constando histórico, série, número de ordem, número de página e volume da revista em que foi publicado. (Não atualizado, nem conservado por falta de auxiliares, em 1972).

\section{Arquivos:}

De cartas e oficios recebidos - 79 pastas "securit cabidex", por ordem geográfica; 1.550 cartas arquivadas. Em 1972 foram arquivadas 180 cartas.

De relações de material expedido - para o correio, em 19 pastas "securit cabidex" por ordem de número. Em 1972 foram arquivadas 78 relações.

De postais de recebimento - por ordem geográfica e numérica 11.393 postais de procedência internacional, constituindo uma curiosidade filatélica. Em 1972 foram arquivados 2.435 postais referentes a 1971 e 1972 .

De clichês - por série de A a $\mathrm{F}$, conforme dimensão; numerados e arquivados em 18 gavetas, contêm 550 cliches guardados em envelopes especiais, contendo histórico, série, número e página do volume em que foi publicado. Há ainda 400 clichês, aproximadamente, para serem preparados ou identificados. Não atualizado por falta de auxiliares.

De guias da Tesouraria - comprovantes de vendas da Revista da Faculdade de Direito.

De outros documentos, em 11 pastas "securit cabidex".

De trabalhos originais, por ordem de volumes e autores.

De provas tipográficas, por ordem de volumes e autores.

\section{SERVIÇO BIBLIOGRÄFICO}

Embora os catálogos de autor, título e de assunto da "Revista da Faculdade de Direito" estivessem completos até 1968, não se os atualizaram por estar em preparo o Indice Geral, elaborado pela Biblioteca Central.

Aguarda compilação datilografada o segundo Boletim Bibliográfico de Artigos de revistas recebidas em permuta, classificados por matéria, com 4.800 fichas; tem sido solicitado pelos senhores professores, apesar da publicação dos Indices de Periódicos Correntes, pelo Centro de Documentação desta Faculdade.

\section{Do Relatório de 1973}

Verifica-se de ano a ano, através de correspondência recebida, a receptividade cada vez maior da "Revista", nos centros internacionais de cultura jurídica, provada, também, pelo seu registro bibliográfico em publicações de cobertura internacional, tais como:

\footnotetext{
"Urich's International Periodicals Directory" - publicado pela R.D. Bowker Co. - New York.
} 
"Index to Foregn Legal Perodicals" publicado pelo Instituto of Advanced Legal Studies, London, England;

"Sumario Actual de Revistas da Biblioteca Hispânica" publicado pelo Instituto de Cultura Hispanica, Madrid, España;

"Revista Jurídica Panameña" da Universidade do Panama.

Dentre as obras recebidas para resenha, destacaram-se as seguintes:

"Derecho Internacional Privado" de José Yanguas Messia, parte general, 3a edicion, Reus, S.A. Madrid, España, 413 páginas.

"Foundation of Jurisprudence", Jerome Hall; The Bobbs Merril Company Inc., Indiana, USA, 1973, $184 \mathrm{p}$.

"Voting and Decisions in the International Monetary Fund", Joseph Gold, International Monetary Fund, Washington, 1972, $368 \mathrm{p}$.

"Bases para un Nuevo Derecho Penal", Dorado Montero, nueva edicion con prólogo, bibliografia y notas por Manuel de Rivacoba y Rivacoba - Depalma, S.R.L., Buenos Aires, 1973, 171 p.

A resenha dessas obras ficará a cargo de especialistas e será publicado nos próximos números da "RFD"

PERMUTA INTERNACIONAL

Pelos anteriores acordos de permuta que foram estabelecidos mediante criteriosa pesquisa bibliográfica e pela divulgação da "RFD" no Brasil e no exterior, receberam-se, em 1973, 1.560 exemplares de revistas periódicas, nacionais e estrangeiras, versando os mais variados temas de Direito geral e especializado, ou seja, Direito Aeronáutico, Direito Automobilístico, Direito Cinematográfico, Direito Sanitário, Direito Esportivo etc. etc..

Todos os números recebidos foram registrados no livro de tombo e remetidos à Biblioteca Geral, após carimbagem, constituindo o Indice Geral publicado pelo Centro de Documentação Jurídica desta Faculdade, em sua maior parte. Impraticável é relacionar todos os títulos por tratar-se de centenas, mas como índice de avaliação, relacionam-se a seguir apenas as novas revistas recebidas em 1973 e registradas em novembro:

- "Annales Universitatis Scientiarum Budapestinensis de Rolando Eotvos Nominatae" - Sectio Juridica, 1972, Budapest.

- "Revista del Instituto de Historia del Derecho Ricardo Levene" - Facultad de Derecho y C. Sociales - Universidad de Buenos Aires - Argentina, 1972.

- "Travaux de la Societé des Sciences et des Lettres de Wroclaw" - Seria A. no 86 - L'Acte Administratif dans le Réseau Etatique de L'Economie Nationale Wroclaw, 1972.

- "Revista de Derecho Administrativo y Fiscal" - La Coruña, 1972, España.

- "Revue Roumaine des Sciences Sociales", Sciences Juridiques, Bucarest, Roumanie, 1973.

- "Revista di Filosofia Neo Scolastica", Università Cattolica del Sacro Cuore, Milano, Itália, 1973.

- "Philippine Law Journal", College of Law, University of the Philipines, Quezon Philippines, 1972.

- "Annales de Droit", Faculté de Droit de l'Université Catholique de Louvain, 1973, Louvain, Belgique.

- "Journal of World Trade Law", 1973, Twickenhaw, Middlesex, England. 
- "International Affairs", Oxford University Press, London, England, 1973.

- "Foreign Affair", An American Quarterly Review, New York, 1973.

- "Zeistschrift fur das Gesamte Handelsrecht und Wirtschafts recht", 1973, Stuttgart, Germany.

- "The Sydney Law Review", Faculty of Law, University of Sydney, 1973, Sydney, Australia.

- "Etudes Internationales", Centre Quebecois de Droit International, (digo), de Relations Internationales, 1973, Quebec, Canadá.

- "Ius Canonicum", Instituto Martin de Azpilcueta, Universidad de Navarra, Pamplona, España, 1973.

- "Studia et Documenta Historiae et Juris", Pontificium Institutum Utriusque Juris, 1972, Roma - Itália.

- "Archiv fur Rechts - und Sozialphilosophie", 1973, Deutsche Forschungsgemeinschaft, bibliotheksreferat, Bonn.

- "Revista de Derecho", Facultad de Jurisprudencia y Ciencias Sociales de la Universidad de El Salvador, 1973, San Salvador, Salvador.

- "Annales de la Faculté de Droit et des Sciences Economiques", Faculté de Droit Départment des Sciences Economiques - Institut d'Administartion. - Université de Lyon - France,

- "Northwest Review", University of Oregon, Eugene, Oregon, 1973.

- "Il Diritto di Autore", Società Italiana degli Autori ed Editore, 1973, Roma, Itália.

- "Il Diritto Sanitario Moderno", 1973, Roma - Itália.

- "Politeia", Instituto de Estudos Politicos - Faculdad de Derecho - Universidad Central de Venezuela - 1973, Caracas, Venezuela.

Em 1977, quando se festejava o sesquicentenário de fundação dos cursos jurídicos, publicou-se volume comemorativo em dois fascículos e mudou-se a capa da revista. Procurou-se fazê-la como as capas dos programas e convites para os festejos, as quais reproduziam parte das Arcadas.

Como nenhum de nossos clichês servisse, e houvesse um problema qualquer de última hora com a impresão de um dos convites, foi então minha sobrinha, Thais Rebello, hoje diretora de arte da Revista Senhor que fotografou um ângulo das Arcadas tanto para o convite como para a capa de nossa Revista, impressa em três cores: vermelha, preta e branca, identificando-a significativamente.

A apresentação desse volume foi feita pelo Professor Dr. Ruy Barbosa Nogueira, então diretor da Faculdade.

A Revista da Faculdade de Direito sempre fez questão de homenagear os professores que completavam 25 anos de ensino universitário, ou recebiam título de professor emérito, e também "post-mortem", os que completavam centenário de nascimento. Em geral publicava-se um resumo biobibliográfico e retrato do homenageado, ou fazia-se a crônica da sessão solene de homenagem. Logo de início, 
em 1954, publicou-se a posse de cátedra do Professor Goffredo Telles Júnior e, recentemente, como uma das últimas homenagens, a do jubileu de cátedra. Desde lá, 1954 até 1981, tive a honra de publicar a posse de cátedra de todos os professores da Congregação, excluindo apenas o Professor Dr. Dalmo de Abreu Dallari em 1974 ou 1975.

Os professores vivos homenageados pela Revista remetem ao Redator Secretário seu currículo profissional, mas esquecem-se de esclarecer pelo menos alguns pontos de sua personalidade ou fatos de sua vida. Devendo o Redator traçar-lhes o perfil, como fazê-lo sem informes de personalidade ou de vida?

Ressenti-me disto, sempre, por isso relatei certos fatos de minha vida que aparentemente nada têm a ver com a parte profissional mas revelam facetas de personalidade. Ora, no trabalho profissional de todas as pessoas relacionam-se intrinsicamente formação, personalidade, vida pregressa familiar e educacional, responsáveis pelo sucesso ou insucesso do desempenho.

O homem, ensina a Filosofia do Direito, "é ele mesmo e suas circunstâncias".

\section{Conclusão e Agradecimento}

Encerro afinal esta longa etapa da vida, com a consciência de ter usado toda capacidade física, mental e intelectual a serviço da Pátria e do Direito, fazendo minha parte como o pássaro da fábula fez a sua, ao transportar no bico gotas de água de um rio para apagar incêndio na floresta.

Com infinita gratidão a meus pais pelo amor e sacrifícios que me deram; a meus irmãos, parentes e amigos pelo carinho e apoio de sempre; a cada um dos funcionários que me ajudaram tanto, cada qual dando o melhor de si; a cada colega de trabalho e estudos, co-participantes de vida; a cada um dos professores, desde o primário até as Universidades, aos quais reverto eventual mérito dos trabalhos; ao Bacharel, Jornalista, colega, ex-auxiliar e sucessor, Antonio Augusto Machado de Campos, a quem atribuo parte da iniciativa desta publicação; muito especialmente ao DD. Diretor desta Faculdade, Professor Dr. Vicente Marotta Rangel, à Congregação de Professores e à Comissão de Redação, atuais e passadas, a atenção e assistência com que me distinguiram e a honra de publicar em sua Revista Minha Vida - Meu Trabalho. Mas é a Deus, com todo meu ser, que agradeço a realização dos sonhos da mocidade, e o permitir-me chegar até aqui.

Finalmente, "deixo a folha dobrada" enquanto lágrimas reprimidas se desfazem em saudade no meu peito, mas, arde ainda a pira do amor, haverá estrelas no céu da noite que se aproxima.

\section{Maria Angélica Rebello}

Bacharel em Direito e Jornalismo, ex-Redator Secretário da Revista da Faculdade de Direito 